\title{
Volatile Organic Compound (VOC) measurements in the Pearl River Delta (PRD) region, China
}

\author{
Ying Liu ${ }^{1}$, Min Shao ${ }^{1}$, Sihua Lu ${ }^{1}$, Chih-chung Chang ${ }^{2}$, Jia-Lin Wang ${ }^{3}$, and Gao Chen ${ }^{4}$ \\ ${ }^{1}$ State Joint Key Laboratory of Environmental Simulation and Pollution Control, College of Environmental Sciences and \\ Engineering, Peking University, Beijing, China \\ ${ }^{2}$ Research Center of Environment Change, Academia Sinica, Nankang, Taipei 115, Taiwan \\ ${ }^{3}$ Department of Chemistry, National Central University, Chungli 320, Taiwan \\ ${ }^{4}$ NASA Langley Research Center, Hampton, VA 23681, USA
}

Received: 3 September 2007 - Published in Atmos. Chem. Phys. Discuss.: 16 October 2007

Revised: 6 February 2008 - Accepted: 13 February 2008 - Published: 13 March 2008

\begin{abstract}
We measured levels of ambient volatile organic compounds (VOCs) at seven sites in the Pearl River Delta (PRD) region of China during the Air Quality Monitoring Campaign spanning 4 October to 3 November 2004. Two of the sites, Guangzhou (GZ) and Xinken (XK), were intensive sites at which we collected multiple daily canister samples. The observations reported here provide a look at the VOC distribution, speciation, and photochemical implications in the PRD region. Alkanes constituted the largest percentage $(>40 \%)$ in mixing ratios of the quantified VOCs at six sites; the exception was one major industrial site that was dominated by aromatics (about 52\%). Highly elevated VOC levels occurred at GZ during two pollution episodes; however, the chemical composition of VOCs did not exhibit noticeable changes during these episodes. We calculated the $\mathrm{OH}$ loss rate to estimate the chemical reactivity of all VOCs. Of the anthropogenic VOCs, alkenes played a predominant role in VOC reactivity at GZ, whereas the contributions of reactive aromatics were more important at XK. Our preliminary analysis of the VOC correlations suggests that the ambient VOCs at GZ came directly from local sources (i.e., automobiles); those at XK were influenced by both local emissions and transportation of air mass from upwind areas.
\end{abstract}

\section{Introduction}

The Pearl River Delta (PRD) is located in Southern China, extends from the Hong Kong metropolitan area to the northwest, and encompasses 9 cities in the Guangdong Province (Fig. 1). The PRD region has an area of about $41698 \mathrm{~km}^{2}$

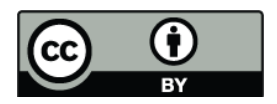

Correspondence to: Min Shao (mshao@pku.edu.cn) and a population of about 45.5 million. It has been the most economically dynamic region of mainland China over the last two decades, with a per capita GDP of US\$ 6583 in 2004. The average annual rate of GDP growth in the PRD from 2000 to 2004 was $13.6 \%$, which is well above the national GDP growth rate (8.6\%) (China Yearbook of Statistics, 2004). Guangzhou (GZ), the capital of Guangdong Province, had the highest GDP value (US \$ 496 billion) in the PRD region in 2004. Dongguan (DG) is the city with the fastest growth rate GDP (18.7\% per year from 2002-2006); it is a major manufacturing base for a wide range of products, including electronics, communication, paper, garments and textiles, food, shoes, and plastic.

Associated with the rapid economic development are the high levels of $\mathrm{PM}_{2.5}$ and ozone that have been observed in the PRD region over the past decade (Wang et al., 2003). Concentrations of ozone at GZ rose dramatically during the 1990s. For example, daily average $\mathrm{O}_{3}$ concentrations exceeded the second level criterion ( $80 \mathrm{ppbv}$, hourly) of the Chinese National Ambient Air Quality Standard (NAAQS) on at least 5 days in October 1995 (Zhang et al. 1998). Between October and December 2001, the highest hourly $\mathrm{O}_{3}$ average reached $142 \mathrm{ppbv}$ at Tai $\mathrm{O}$, a rural/coastal site in southwest Hong Kong on the north-south centerline of the Pearl Estuary (Wang et al., 2003). The daily concentrations of $\mathrm{PM}_{2.5}$ observed in downtown of GZ reached $111 \mu \mathrm{g} / \mathrm{m}^{3}$ in 2002, which is nearly twice the level recommended by the US EPA (65 $\mu \mathrm{g} / \mathrm{m}^{3}$, daily) (Li et al., 2005). Such high levels of air pollutants present a serious public health issue.

$\mathrm{NO}_{\mathrm{x}}$ and volatile organic compounds (VOCs) are important precursors of ground-level ozone. The VOC impact on ozone is closely related to the magnitude and the species emitted from various sources. For instance, liquefied petroleum gas (LPG) leakage played an important role

Published by Copernicus Publications on behalf of the European Geosciences Union. 


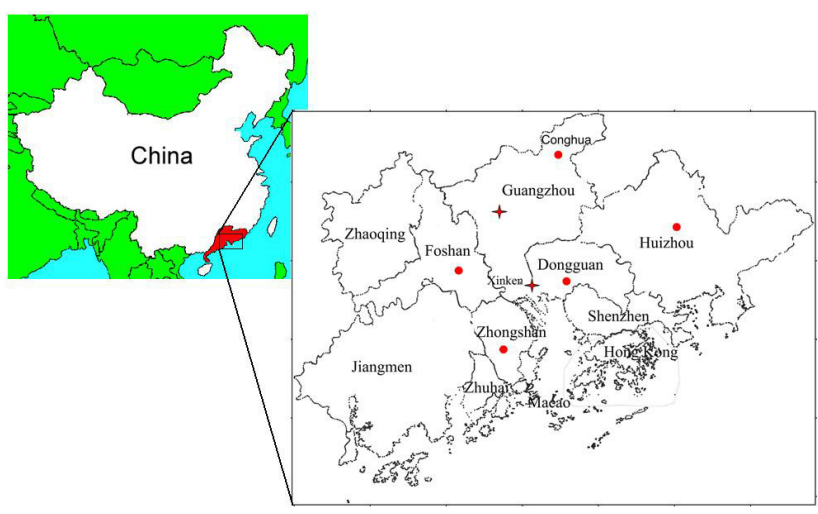

Fig. 1. Location of sites for the 2004 Air Quality Monitoring Campaign in the Pearl River Delta (PRD). The star indicates intensive sites, and the dots indicate sites for regional distribution sampling.

in causing excessive ozone in Mexico City and in Santiago, Chile (Blake and Rowland, 1995; Chen et al., 2001). The continuous high levels of atmospheric $\mathrm{O}_{3}$ in summer in Houston, Texas were caused mainly by reactive VOCs emitted by petrochemical industries (Ryerson et al., 2003; Jobson et al., 2004), and vehicular emissions have contributed more than 50\% of ambient VOCs in Beijing city (Liu et al., 2005). Other studies have indicated the importance of biogenic sources of VOCs (Chameides et al., 1988; Shao et al., 2000; Warneke et al., 2004; de Gouw et al., 2005).

In the PRD, VOC speciation and sources have been quite intensively studied. The most representative work, which was conducted in 2000 (Chan et al., 2006), provided the first snapshot of VOC concentrations in industrial, industrialurban, and industrial-suburban areas and discussed the importance of industrial and vehicular emissions in shaping the spatial variation of VOCs. The measurements at Tai O (Wang et al., 2005; Guo et al., 2006) which lies between the PRD region and Hong Kong urban center, illustrated how the characteristics of air masses varied with their point of origin, especially in terms of the differences in regional and local contributions to ambient VOCs at the site.

Due to the complexity of VOC variation and the rapid changes in VOC sources in the PRD region, more simultaneous measurements of ambient VOCs with $\mathrm{CO}, \mathrm{NOx}$, and $\mathrm{O}_{3}$ are needed. An understanding of local VOC source profiles will be helpful in interpreting the sources of VOCs in ambient measurements. The PRD air quality monitoring campaign of 2004 represents the first regional study in China designed to gain a better understanding of how ground-level ozone is formed and to determine the sources of fine particles. The measurement of PRD VOCs was a joint effort by the College of Environmental Sciences and Engineering (CESE) of Peking University (PKU); the Research Center for Environmental Changes of Academia Sinica (RCEC), Taiwan; and the Department of Chemistry of National Central University, Taiwan. Herein we present the data on VOC dis- tribution and speciation obtained at seven PRD sites and we discuss their potential photochemical impacts. We explored the contributions of various VOC sources by analyzing correlations between VOC species as well as the co-variations between VOC species and other gaseous pollutants.

\section{Field measurements}

\subsection{Sampling sites}

We sampled VOCs at seven sites in the PRD during October and November 2004 (Fig. 1). Two of them - Guangzhou (GZ) and Xinken (XK) - were intensive sites, at which three daily whole air sample (WAS) canisters were collected from 4 October to 3 November 2004. We also measured air pollution tracers, including $\mathrm{NO}, \mathrm{NO}_{\mathrm{y}}, \mathrm{O}_{3}, \mathrm{CO}$, and $\mathrm{SO}_{2}$, at the intensive sites. The GZ and XK sites were thought to be representative of a major metropolitan emission site and a receptor site, respectively. We collected VOC samples at the other five sites at the end of October. These five sites were Conghua $(\mathrm{CH})$, Huizhou (HZ), Foshan (FS), Zhongshan (ZS), and Dongguan (DG).

Guangzhou is situated at the coast of the South China Sea $\left(21 \sim 23^{\circ} \mathrm{N}\right)$ and experiences a typical sub-tropical climate. The GZ site is located in the downtown area of the city. We collected canister samples at the roof of a 17-floor building (about $55 \mathrm{~m}$ above ground). Xinken lies in a less populated coastal area; it is a rural site located $\sim 50 \mathrm{~km}$ to the southeast of the city center. Ambient air was drawn at the third floor platform of a building (about $10 \mathrm{~m}$ above ground). $\mathrm{CH}$ is a rural site and $\mathrm{HZ}$ is a suburban one, and both are located upwind of the PRD region. We chose DG to examine industrial emissions. FS and ZS, like GZ, are urban sites.

During the PRD air quality monitoring campaign of 2004, abundant sunshine, mild temperature and breeze, and no precipitation characterized the weather. Under the influence of a high-pressure system and stagnant conditions, the boundary layer height was generally within $1 \mathrm{~km}$. At GZ, a northerly wind prevailed (mainly between NNW and NNE) and weakened during the daytime. At XK, a northeasterly wind was dominant (often between $\mathrm{N}$ and NE) in the morning, and a sea breeze (a SE or ESE air stream) was observed in late afternoon.

\subsection{Sampling methods}

We collected WAS in fused silica-lined stainless steel canisters $(2 \mathrm{~L}, 3.2 \mathrm{~L}$, or $6 \mathrm{~L})$. The canisters were evacuated to $<100$ mtorr, and then pressurized to $\sim 30$ psi with humid nitrogen at $95^{\circ}$. After three cycles of filling and evacuation, the canisters were ready for sample collection, with final vacuums of $<50$ mtorr. The stabilities of canister samples had been examined by repetitive measurements of calibration gas or ambient sample from canisters every several days after filling. Most of target compounds had good recoveries of more 
than $87 \%$ over 30 days, and these results are consistent with those in some earlier studies (Greenberg et al., 1992; Blake et al., 1994; Batterman et al., 1998; Ochiai et al., 2002). An ozone scrubber $\left(\mathrm{Na}_{2} \mathrm{SO}_{3}\right.$ trap) was installed in the sample line to remove ozone, and a passive capillary (calibrated in advance) was connected to the canister to keep the sampling air flow rate constant.

Each day from 4 October to 3 November 2004, routine samples were collected for $60 \mathrm{~min}$ at 05:30, 07:30, and 14:00 in GZ and at 07:30 and 14:00 in XK. The samples to examine diurnal variation were taken every $2 \mathrm{~h}$ for $30 \mathrm{~min}$ from $06: 00$ to 22:00 at GZ and XK on 9 October, 21 October, and 3 November 2004. The samples at CH, HZ, FS, and ZS were drawn for $60 \mathrm{~min}$ at 08:00 and 17:00 on 20-22 October 2004. Air samples were collected for $60 \mathrm{~min}$ at 08:30 and 16:30 at DG on 3-4 November 2004.

\subsection{Quantification of VOC species}

The analysis of the canister samples was conducted in a laboratory at PKU. Up to 134 species of VOCs were detectable using a cryogenic pre-concentrator (Entech Instrument 7100A, SimiValley, CA) and a gas chromatograph (Hewlett Packard 6890) equipped with two columns and two detectors (see detailed description in Liu et al. (2005)). The $\mathrm{C}_{2}-\mathrm{C}_{4}$ alkanes and alkenes were separated on a nonpolar capillary column (HP-1, $50 \mathrm{~m} \times 0.32 \mathrm{~mm} \mathrm{ID} \times 1.05 \mu \mathrm{m}$, $\mathrm{J} \& \mathrm{~W}$ Scientific) and quantified with a flame ionization detector (FID). The $\mathrm{C}_{5}-\mathrm{C}_{12}$ hydrocarbons were separated on a semi-polar column (DB-624, $60 \mathrm{~m} \times 0.32 \mathrm{~mm} \mathrm{ID} \times 1.8 \mu \mathrm{m}$, $\mathrm{J} \& \mathrm{~W}$ Scientific) and quantified using a quadrupole mass spectrometer (MS, Hewlett Packard 5973), which was operated in Selected Ion Mode (SIM) with a maximum of six ions being monitored for each time window. Three VOC compounds were used as internal standards in calibration of our analytical system, namely bromochloromethane, 1,4difluorobenzene and 1-bromo-3-fluorobenzene.

First, ambient air samples and internal standards were pumped into the pre-concentrator, which has 3-stage cryotraps (Module 1 3). VOC compounds were initially trapped cryogenically on glass beads of Module 1 at $-180^{\circ} \mathrm{C}$ by liquid nitrogen; then they were recovered by desorbing at $20^{\circ} \mathrm{C}$ to leave most of the liquid $\mathrm{H}_{2} \mathrm{O}$ behind in the first trap. The second cryotrap, which contains Tenax, was cooled to $-30^{\circ} \mathrm{C}$, which allows trapping of VOCs while letting $\mathrm{CO}_{2}$ pass through. From Module 2, VOCs were backflushed at $180^{\circ} \mathrm{C}$ then focused again at $-180^{\circ} \mathrm{C}$ in the Module 3 trap. The Module 3 trap then was rapidly heated to $60 \sim 70^{\circ} \mathrm{C}$ in $30 \mathrm{~s}$. Helium was used as the purge gas for the cryogenic pre-concentrator and the carrier gas for the GC. Column HP1 was initially held at $-50^{\circ} \mathrm{C}$ for $3 \mathrm{~min}$, then was raised to $164^{\circ} \mathrm{C}$ at a rate of $6^{\circ} \mathrm{C} / \mathrm{min}$; then to $200^{\circ} \mathrm{C}$ at a rate of $14^{\circ} \mathrm{C} / \mathrm{min}$, and finally was held for $0.5 \mathrm{~min}$. Column DB-624 was programmed to move from $30^{\circ} \mathrm{C}$ to $180^{\circ} \mathrm{C}$ at a rate of $6^{\circ} \mathrm{C} / \mathrm{min}$ and then was held for $5 \mathrm{~min}$ at $180^{\circ} \mathrm{C}$.

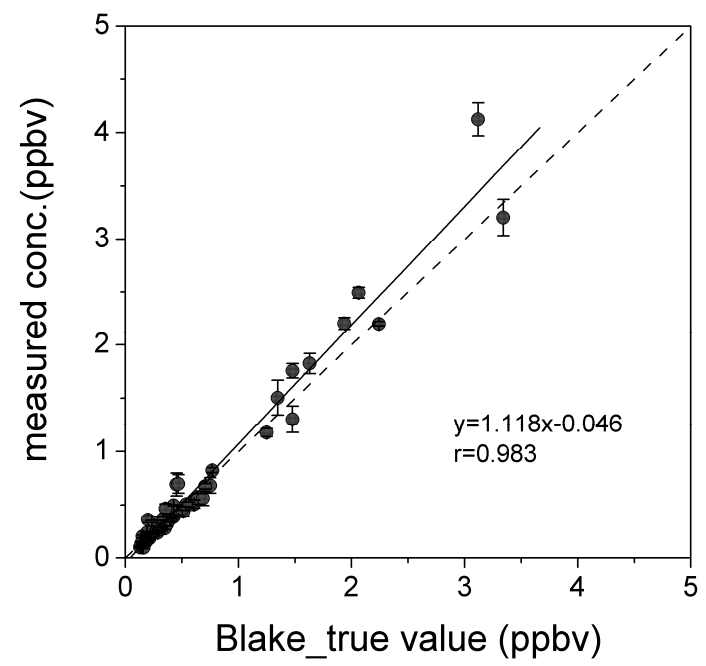

Fig. 2. Correlation of the measured and reference concentrations of 55 NMHCs in standard gas.

Table 1 summarizes the full list of the 134 VOC species that were identified and quantified using a certificated standard of VOC mixture in ambient concentration (provided by the Environmental Technology Center, Canada). We performed calibrations at five concentrations from 0.1 to 25 ppbv for each compound before sample analysis. Correlation coefficients, which ranged from 0.996 to 1.000 , showed that integral areas of peaks were proportional to concentrations of target compounds. The definition of the method detection limit (MDL) for each compound is given in EPA TO15 , and the MDL for all measured VOC species ranged from 0.009 to $0.057 \mathrm{ppbv}$. The response of the instrument to VOCs was calibrated after every eight samples using standard runs of a calibration gas with ambient concentrations.

\subsection{Inter-comparison experiment}

To ensure the quality of the data, we conducted measurement comparison exercises for both standard mixtures and ambient samples. Two planned experiments were involved: 1) analysis at PKU of a known standard gas (provided by D. R. Blake's group from the Department of Chemistry, University of California at Irvine (UCI)); and 2) a blind intercomparison of WAS results measured separately by PKU and RCEC.

Figure 2 shows the measurements made at PKU for 55 NMHC species in standard gas obtained from UCI; each point represents one species, and error bars were computed from over seven replicate measurements. The correlation between measured concentrations analyzed at the PKU lab and the reference values were good $\left(R^{2}=0.96\right)$, and the averaged slope was $1.09 \pm 0.04$. The measured concentrations of alkanes were very close to their reference values, and the relative standard deviation ranged from $0.9 \%$ to $9.6 \%$. The relative 
Table 1. VOC species quantified by the GC-MS/FID system.

\begin{tabular}{|c|c|c|c|}
\hline Alkanes & Alkenes & Aromatics & Halides \\
\hline Ethane & Ethylene & Benzene & Chloromethane \\
\hline Propane & Propene & Toluene & Bromomethane \\
\hline Isobutane & 1-Butene/Isobutene & Ethylbenzene & Chloroethane \\
\hline n-Butane & 1,3-Butadiene & m/p-Xylene & Bromoethane \\
\hline 2,2-Dimethylpropane & trans-2-Butene & o-Xylene & 1,1-Dichloromethane \\
\hline 2-Methylbutane & cis-2-Butene & Styrene & 1,1-Dichloroethane \\
\hline Pentane & 3-Methyl-1-butene & Isopropylbenzene & Chloroform \\
\hline 2,2-Dimethylbutane & 1-Pentene & n-Propylbenzene & 1,1,1-Trichloroethane \\
\hline 2,3-Dimethylbutane & 2-Methyl-1-butene & 3-Ethyltoluene & Carbontetrachloroide \\
\hline 2-Methylpentane & trans-2-Pentene & 4-Ethyltoluene & 1,2-Dichloropropane \\
\hline 3-Methylpentane & Isoprene & 1,3,5-Trimethylbenzene & Dibromomethane \\
\hline n-Hexane & cis-2-Pentene & 2-Ethyltoluene & Bromodichloromethane \\
\hline 2,2-Dimethylpentane & 2-Methyl-2-butene & tert-Butylbenzene & 1,1,2-Trichloroethane \\
\hline 2,4-Dimethylpentane & 4-Methyl-1-pentene & 1,2,4-Trimethylbenzene & Dibromochloromethane \\
\hline Methylcyclopentane & 3-Methyl-1-pentene & iso-Butylbenzene & 1,2-Dibromoethane \\
\hline 2-Methylhexane & Cyclopentene & sec-Butylbenzene & 1,4-Dichlorobutane \\
\hline Cyclohexane & trans-4-Methyl-2-pentene & p-Cymene & 1,1,2,2-Tetrachloroethane \\
\hline 2,3-Dimethylpentane & cis-4-Methyl-2-pentene & 1,2,3-Trimethylbenzene & 1,1-dichloroethylene \\
\hline 2,2-Dimethylhexane & 2-Methyl-1-pentene & 1,3-Diethylbenzene & cis-1,2-dichloro-ethene \\
\hline n-Heptane & 2-Ethyl-1-butene & 1,4-Diethylbenzene & Trichloroethylene \\
\hline 2,5-Dimethylhexane & trans-2-Hexene & n-Butylbenzene & tans-1,3-Dichloropropene \\
\hline Methylcyclohexane & trans-3-Methyl-2-pentene & 1,2-Diethylbenzene & Tetrachloroethylene \\
\hline 2,3,4-Trimethylpentane & cis-2-Hexene & Indan & \\
\hline 2-Methylheptane & cis-3-Methyl-2-pentene & & \\
\hline 4-Methylheptane & 1-Methylcyclopentene & Alkynes & Chlorinated aromatics \\
\hline 3-Methylheptane & Cyclohexene & Acetylene & Chlorobenzene \\
\hline c-1,3-Dimethylcyclohexane & 1-Heptene & Propyne & 1,3-Dichlorobenzene \\
\hline t-1,4-Dimethylcyclohexane & trans-2-Heptene & 1-Butyne & 1,4-Dichlorobenzene \\
\hline Octane & cis-2-Heptene & & Benzylchloride \\
\hline t-1,2-Dimethylcyclohexane & 1-Methylcyclohexene & Chlorofluorocarbons (CFCs) & 1,2-Dichlorobenzene \\
\hline c-1,4/1,3-Dimethylcyclohexane & 1-Octene & Dichlorodifluoromehtane & \\
\hline c-1,2-Dimethylcyclohexane & trans-2-Octene & Chlorodifluoromethane & Others \\
\hline n-Nonane & 1-Nonene & 1,2-dichloro-1,1,2,2-tetrafluoro-ethane & Acetonitrile \\
\hline 3,6-Dimethyloctane & a-Pinene & Trichlorofluoromehtane & MTBE \\
\hline n-Decane & Camphene & 1,1,2-trichloro-1,2,2-trifluoro-ethane & \\
\hline \multirow[t]{3}{*}{ Dodecane } & b-Pinene & & \\
\hline & Limonene & & \\
\hline & 1-Undecene & & \\
\hline
\end{tabular}

errors of n-butane, i-butane, n-pentane, 2-methyl pentane, and 2-mehtyl hexane were below 5\%; for $>\mathrm{C} 7$ alkanes the relative errors were usually between $5.7 \%$ and $9.9 \%$. The deviations of 1-butene/i-butene, trans-2-butene, 1-pentene, and 2-methyl-1-butene were $4.5 \%, 9.1 \%, 5.9 \%$, and $9.5 \%$, respectively. For isoprene and $\alpha$-pinene, the deviations from the reference values were relatively larger, reaching $10.7 \%$ and $13.4 \%$, respectively. The averaged deviations of aromatics were about $10 \%$. Several scattered points, such as those of cyclopentene, which deviated from the 1:1 dashed line in Fig. 2, indicate the difference of the standards used at PKU and RCEC lab to calibrate the NMHC species.
Both PKU and RCEC measured 50 VOC species from the same 16 ambient canisters samples. Figure 3 shows the results for some of the NMHC compounds. For most of the alkanes, the slopes of the linear regression for PKU versus RCEC measurements fell between 0.87 and 1.11, with $R^{2}$ values over 0.9 . For reactive alkene and aromatics compounds, including butenes, cis-2-pentene, 3-methyl1-butene, benzene, toluene, xylenes, and trimethylbenzenes, the measured mixing ratios calculated by the two labs also agreed well within the combined uncertainties for each system. However, the average $\alpha$-pinene concentration measured at PKU was about $30 \%$ lower than that from RCEC lab. 

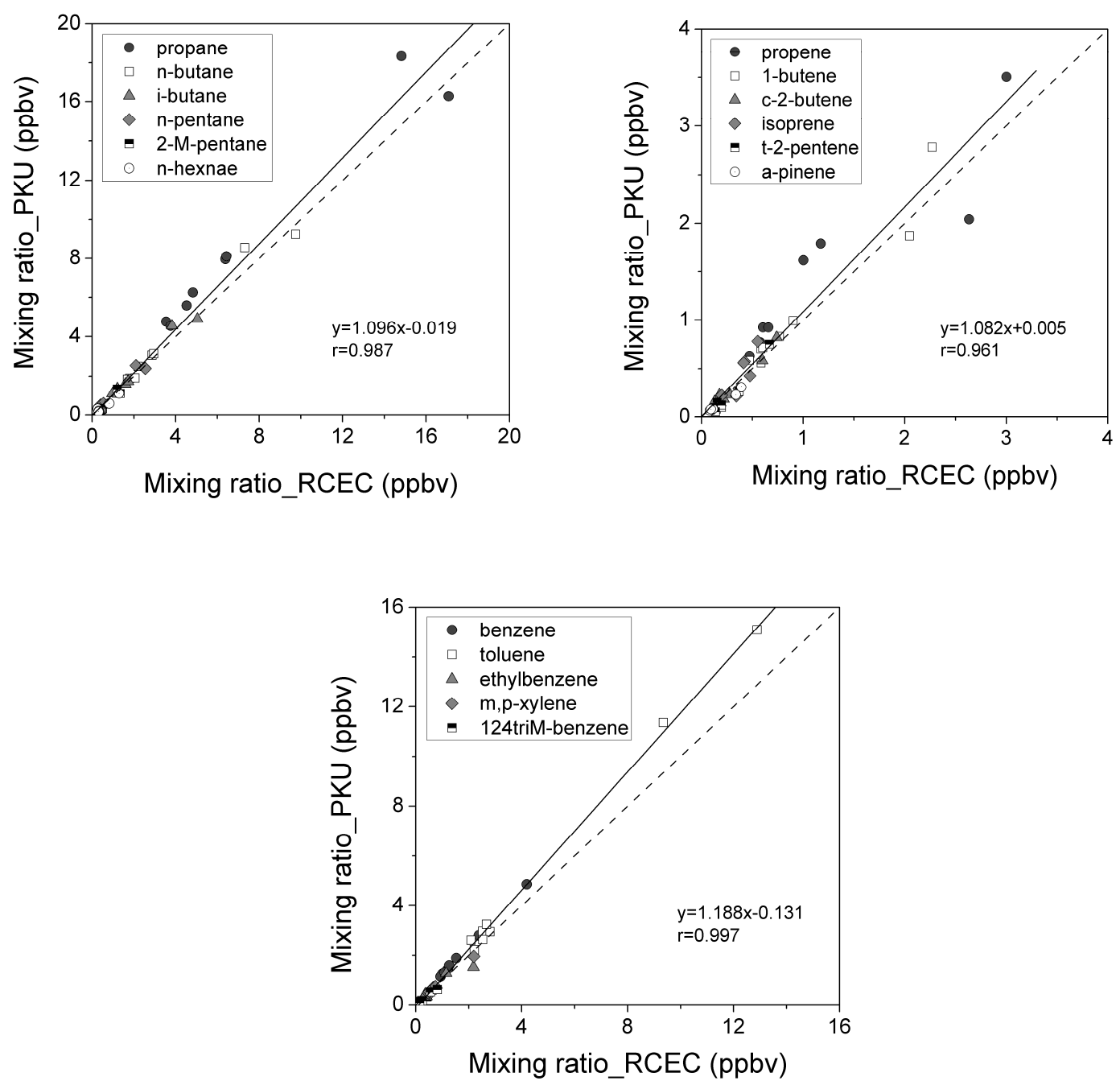

Fig. 3. Comparison of parallel WAS canisters between PKU and RCEC results for some (a) alkanes, (b) alkenes, and (c) aromatics.

\section{Results and discussion}

3.1 Mixing ratios of VOC species at Guangzhou and Xinken

Figure 4 shows the averages of the total quantified PRD VOC mixing ratios and the relative contributions from the major VOC groups. The highest total VOC mixing ratio was measured at DG (an industrial area), followed by the major urban site GZ. The levels at XK, FS, and ZS were quite similar to each other. All three sites lie downwind of industrial areas and/or major urban centers. The two lowest VOC values were recorded in $\mathrm{CH}$ and $\mathrm{HZ}$, which lie upwind of the major cities.

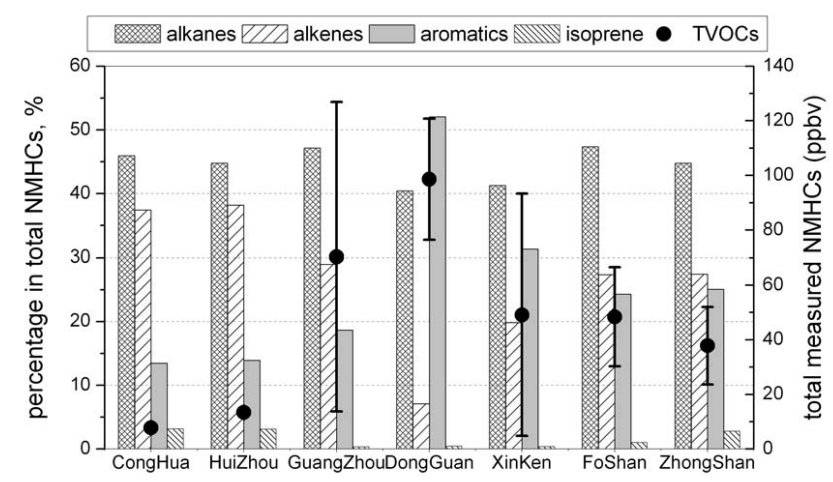

Fig. 4. Regional distribution of mixing ratio (in volume percentage) and chemical composition of VOCs at seven sites. 
Table 2. The method detection limits (MDL; ppbv) and average mixing ratios of 54 NMVOCs measured at Guangzhou (GZ) and Xinken (XK).

\begin{tabular}{|c|c|c|c|c|c|}
\hline & & GZ & GZ & $\mathrm{XK}$ & $\mathrm{XK}$ \\
\hline Species & MDL (ppbv) & range & average \pm s.d. & range & average \pm s.d. \\
\hline Ethane & 0.014 & $1.35-25.80$ & $5.58 \pm 3.34$ & $1.54-10.15$ & $3.07 \pm 1.26$ \\
\hline propane & 0.010 & $3.16-57.24$ & $10.35 \pm 8.53$ & $0.99-15.14$ & $3.51 \pm 2.90$ \\
\hline Isobutane & 0.016 & $0.70-17.09$ & $2.93 \pm 2.57$ & $0.21-6.26$ & $1.26 \pm 1.23$ \\
\hline n-Butane & 0.035 & $1.19-28.30$ & $5.07 \pm 4.42$ & $0.38-13.51$ & $2.71 \pm 2.79$ \\
\hline 2-Methylbutane & 0.032 & $0.55-12.15$ & $2.62 \pm 2.24$ & $0.23-7.91$ & $1.45 \pm 1.42$ \\
\hline Pentane & 0.011 & $0.21-4.67$ & $1.19 \pm 1.07$ & $0.09-5.98$ & $1.10 \pm 1.25$ \\
\hline 2,2-Dimethylbutane & 0.024 & $0.01-0.38$ & $0.09 \pm 0.07$ & n.a. -0.38 & $0.07 \pm 0.07$ \\
\hline 2,3-Dimethylbutane & 0.015 & $0.05-1.06$ & $0.26 \pm 0.24$ & $0.01-1.09$ & $0.19 \pm 0.20$ \\
\hline 2-Methylpentane & 0.019 & $0.18-4.44$ & $1.03 \pm 0.94$ & $0.07-5.46$ & $0.83 \pm 0.92$ \\
\hline 3-Methylpentane & 0.016 & $0.08-2.80$ & $0.67 \pm 0.64$ & $0.03-3.76$ & $0.61 \pm 0.69$ \\
\hline n-Hexane & 0.024 & $0.11-3.45$ & $0.84 \pm 0.80$ & $0.04-5.83$ & $0.89 \pm 1.03$ \\
\hline Methylcyclopentane & 0.011 & $0.06-2.00$ & $0.53 \pm 0.49$ & $0.01-2.72$ & $0.39 \pm 0.47$ \\
\hline 2-Methylhexane & 0.012 & $0.06-2.33$ & $0.56 \pm 0.55$ & $0.02-4.14$ & $0.56 \pm 0.71$ \\
\hline Cyclohexane & 0.011 & $0.02-1.15$ & $0.21 \pm 0.21$ & n.a. -1.32 & $0.20 \pm 0.24$ \\
\hline 2,3-Dimethylpentane & 0.010 & $0.03-5.28$ & $0.92 \pm 1.19$ & $0.02-9.30$ & $0.79 \pm 1.34$ \\
\hline n-Heptane & 0.009 & $0.07-2.53$ & $0.63 \pm 0.61$ & $0.02-4.04$ & $0.57 \pm 0.71$ \\
\hline Methylcyclohexane & 0.013 & $0.04-1.89$ & $0.38 \pm 0.34$ & n.a.-1.81 & $0.23 \pm 0.31$ \\
\hline 2-Methylheptane & 0.015 & $0.02-0.72$ & $0.15 \pm 0.14$ & n.a. -0.78 & $0.10 \pm 0.13$ \\
\hline Octane & 0.009 & $0.03-0.86$ & $0.18 \pm 0.15$ & $0.02-1.09$ & $0.15 \pm 0.20$ \\
\hline n-Nonane & 0.017 & $0.01-0.44$ & $0.12 \pm 0.08$ & $0.01-0.73$ & $0.10 \pm 0.11$ \\
\hline n-Decane & 0.009 & $0.02-0.43$ & $0.10 \pm 0.09$ & n.a. -1.03 & $0.10 \pm 0.16$ \\
\hline Ethene & 0.027 & $1.95-28.35$ & $6.55 \pm 4.82$ & $0.64-13.11$ & $2.68 \pm 2.19$ \\
\hline Propene & 0.018 & $0.45-17.88$ & $3.02 \pm 2.84$ & $0.14-5.49$ & $0.87 \pm 0.86$ \\
\hline 1-Butene/Isobutene & 0.020 & $0.25-4.44$ & $1.33 \pm 0.91$ & $0.06-1.80$ & $0.44 \pm 0.41$ \\
\hline 1,3-Butadiene & 0.024 & $0.03-0.81$ & $0.20 \pm 0.17$ & n.a.-0.64 & $0.08 \pm 0.11$ \\
\hline trans-2-Butene & 0.009 & $0.02-1.89$ & $0.40 \pm 0.36$ & n.a. -0.34 & $0.06 \pm 0.08$ \\
\hline cis-2-Butene & 0.018 & $0.02-1.87$ & $0.38 \pm 0.33$ & n.a. -0.46 & $0.06 \pm 0.08$ \\
\hline 3-Methyl-1-butene & 0.012 & n.a. -0.38 & $0.09 \pm 0.07$ & n.a. -0.16 & $0.03 \pm 0.03$ \\
\hline 1-Pentene & 0.029 & $0.04-0.73$ & $0.18 \pm 0.14$ & n.a. -0.52 & $0.09 \pm 0.10$ \\
\hline 2-Methyl-1-butene & 0.026 & $0.02-1.08$ & $0.27 \pm 0.23$ & n.a. -0.85 & $0.10 \pm 0.14$ \\
\hline trans-2-Pentene & 0.009 & $0.01-1.12$ & $0.24 \pm 0.23$ & n.a. -0.50 & $0.07 \pm 0.11$ \\
\hline Isoprene & 0.010 & n.a. -0.67 & $0.22 \pm 0.17$ & n.a. -0.80 & $0.17 \pm 0.15$ \\
\hline cis-2-Pentene & 0.006 & n.a. -0.58 & $0.12 \pm 0.12$ & n.a. -0.28 & $0.04 \pm 0.06$ \\
\hline 2-Methyl-2-butene & 0.013 & $0.01-1.35$ & $0.24 \pm 0.29$ & n.a. -0.47 & $0.07 \pm 0.11$ \\
\hline 4-Methyl-1-pentene & 0.021 & $0.02-0.48$ & $0.19 \pm 0.10$ & n.a. -0.90 & $0.18 \pm 0.15$ \\
\hline a-Pinene & 0.009 & n.a. -1.23 & $0.18 \pm 0.18$ & n.a. -1.18 & $0.17 \pm 0.22$ \\
\hline Benzene & 0.014 & $0.66-11.35$ & $2.39 \pm 1.99$ & $0.52-6.26$ & $1.42 \pm 0.98$ \\
\hline Toluene & 0.016 & $0.76-36.91$ & $7.01 \pm 7.33$ & $0.54-56.41$ & $8.46 \pm 9.94$ \\
\hline Ethylbenzene & 0.021 & $0.14-5.20$ & $1.16 \pm 1.22$ & $0.04-13.36$ & $1.62 \pm 2.08$ \\
\hline m/p-Xylene & 0.024 & $0.17-5.19$ & $1.46 \pm 1.42$ & $0.03-17.67$ & $1.94 \pm 2.95$ \\
\hline o-Xylene & 0.023 & $0.07-1.98$ & $0.52 \pm 0.50$ & $0.02-5.87$ & $0.71 \pm 1.02$ \\
\hline Styrene & 0.008 & $0.01-2.30$ & $0.20 \pm 0.37$ & n.a. -2.35 & $0.22 \pm 0.41$ \\
\hline isopropylbenzene & 0.007 & $0.01-0.15$ & $0.04 \pm 0.03$ & n.a. -0.27 & $0.04 \pm 0.05$ \\
\hline n-Propylbenzene & 0.009 & $0.01-0.27$ & $0.06 \pm 0.06$ & n.a. -0.52 & $0.06 \pm 0.08$ \\
\hline 3-Ethyltoluene & 0.015 & $0.02-0.84$ & $0.16 \pm 0.16$ & n.a. -1.04 & $0.10 \pm 0.17$ \\
\hline 4-Ethyltoluene & 0.014 & $0.01-0.30$ & $0.07 \pm 0.06$ & n.a. -0.43 & $0.05 \pm 0.08$ \\
\hline 1,3,5-Trimethylbenzene & 0.020 & $0.02-0.31$ & $0.06 \pm 0.06$ & n.a. -0.46 & $0.05 \pm 0.10$ \\
\hline 2-Ethyltoluene & 0.010 & $0.01-0.29$ & $0.06 \pm 0.06$ & n.a. -0.52 & $0.05 \pm 0.09$ \\
\hline 1,2,4-Trimethylbenzene & 0.029 & $0.02-1.06$ & $0.24 \pm 0.22$ & n.a. -1.81 & $0.18 \pm 0.32$ \\
\hline 1,2,3-Trimethylbenzene & 0.012 & n.a. -0.32 & $0.06 \pm 0.06$ & n.a. -0.58 & $0.05 \pm 0.10$ \\
\hline 1,4-Diethylbenzene & 0.005 & n.a. -1.58 & $0.10 \pm 0.21$ & n.a. -0.67 & $0.08 \pm 0.15$ \\
\hline Chloromethane & 0.020 & $0.80-1.56$ & $1.18 \pm 0.21$ & $0.79-1.64$ & $1.15 \pm 0.22$ \\
\hline Acetonitrile & 0.039 & $0.11-1.57$ & $0.66 \pm 0.29$ & $0.31-1.26$ & $0.66 \pm 0.18$ \\
\hline MTBE & 0.013 & $0.18-5.41$ & $0.96 \pm 0.94$ & n.a. -3.27 & $0.47 \pm 0.61$ \\
\hline
\end{tabular}


Table 3. The 10 most abundant species and CO (ppbv) measured at Guangzhou and at Xinken.

\begin{tabular}{lclllllc}
\hline $\begin{array}{l}\text { Guangzhou, } \\
\text { urban site }\end{array}$ & average & $\begin{array}{l}\text { Xinken, } \\
\text { coastal/suburban site }\end{array}$ & average & $\begin{array}{l}\text { 43 Chinese } \\
\text { cities }^{\mathrm{a}}\end{array}$ & range & $\begin{array}{l}\text { Tai Ob } \mathrm{O}^{\mathrm{b}} \text { Hongkong, } \\
\text { rural/coastal site }\end{array}$ & average \\
\hline Propane & $10.7 \pm 8.9$ & Toluene & $8.3 \pm 9.9$ & Ethane & $3.7-17.0$ & Toluene & $5.6 \pm 7.1$ \\
Acetylene & $7.3 \pm 5.2$ & Acetylene & $4.1 \pm 2.5$ & Acetylene & $2.9-58.3$ & Acetylene & $2.8 \pm 2.0$ \\
Toluene & $7.0 \pm 7.3$ & Propane & $3.5 \pm 2.9$ & Ethylene & $2.1-34.8$ & Ethane & $2.1 \pm 1.0$ \\
Ethylene & $6.8 \pm 5.1$ & Ethane & $3.0 \pm 1.3$ & Propane & $1.5-20.8$ & Propane & $2.0 \pm 2.2$ \\
Ethane & $5.6 \pm 3.3$ & n-butane & $2.7 \pm 2.8$ & Benzene & $0.7-10.4$ & Ethylene & $1.7 \pm 1.7$ \\
n-Butane & $5.2 \pm 4.4$ & Ethylene & $2.7 \pm 2.2$ & Toluene & $0.4-11.2$ & n-Butane & $21.6 \pm 2.1$ \\
Propene & $3.2 \pm 3.0$ & m/p-Xylene & $1.9 \pm 2.9$ & n-Butane & $0.6-14.5$ & Methyl chloride & $0.9 \pm 0.2$ \\
i-butane & $2.9 \pm 2.6$ & Ethylbenzene & $1.6 \pm 2.1$ & i-Butane & $0.4-4.6$ & Ethylbenzene & 0.9 \\
i-Pentane & $2.7 \pm 2.3$ & i-Pentane & $1.5 \pm 1.4$ & i-Pentane & $0.3-18.8$ & Benzene & 0.9 \\
Benzene & $2.4 \pm 1.9$ & Benzene & $1.4 \pm 1.0$ & p-Xylene & $0.2-10.1$ & i-Pentane & 0.8 \\
CO & $867 \pm 552$ & CO & $597 \pm 388$ & & & CO & $525 \pm 323$ \\
\hline
\end{tabular}

a Barletta et al. (2005)

b Guo et al. (2006)

Figure 4 also shows that alkanes constituted the largest group of VOCs at six (CH, HZ, GZ, FS, ZS, and XK) of the seven sites, accounting for over $40 \%$ of the total. In contrast, exceptionally high values of aromatics (about $52 \%$ of the total VOCs) characterized DG, the industrial site. The DG aromatics likely resulted from emissions of the plants associated with textiles, furniture manufacturing, shoemaking, printing, and plastics. XK lies downwind of DG; consequently, it had the second highest faction of aromatics.

Table 2 summarizes the average concentrations and variations of 54 VOCs at GZ and XK, and Table 3 lists the 10 most abundant species observed at these two sites compared with results from previous studies in Hong Kong and other Chinese cities (Barletta et al., 2005; Guo et al., 2006). In general, the PRD VOC mixing ratios fell within the ranges reported for other Chinese cities. A pronounced similarity existed between XK site and Hong Kong's Tai O site. Large fractions of aromatic compounds, especially toluene, were observed at both sites. And XK and Tai O had similar levels of light alkanes as well. Both sites lie downwind from industrial sources of the inner PRD region, which might explain the similarities.

In contrast, GZ had the highest concentration of propane, likely due to the widespread domestic and vehicular use of LPG. High levels of acetylene, toluene, ethylene, and ethane at this site probably originated from several anthropogenic sources such as vehicle exhaust, petrochemical industries, and industrial uses of solvents. Vehicular emissions were clearly identifiable from the significant levels of isobutane, isopentane, and benzene. Finally, CO levels at GZ were about $40 \%$ and $65 \%$ higher than those observed at XK and Tai $\mathrm{O}$, respectively.

\subsection{Time series of VOCs at Guangzhou and Xinken}

Figure 5 displays the time series of $\mathrm{NO}, \mathrm{CO}, \mathrm{O}_{3}$ and VOCs together with meteorological parameters observed at the GZ site. It clearly shows two major pollution episodes characterized by significantly elevated $\mathrm{NO}$ and $\mathrm{CO}$ values. The first episode occurred during 11-13 October and the second one between 28 October and 1 November. The highest hourly averages of VOCs were recorded during the morning hours of episode one (i.e., 05:30 and 07:30 of 11 and 13 October), when wind speed was relatively low $(\sim 1.5 \mathrm{~m} / \mathrm{s})$ and wind direction had mostly switched from northeast or northwest to south or southeast. Those VOC values are about $5 \sim 7$ times higher than the typical values. The elevated VOC levels were also found in the second pollution episode. In contrast, other observed VOC enhancements (e.g., 17 and 24 October) were not associated with highly elevated NO and CO. This suggests that the observed high levels of VOCs may be attributed to different sources or processes. In the case of $\mathrm{O}_{3}$, there were 14 days with hourly averages exceeding $80 \mathrm{ppbv}$, which is the second grade of China's NAAQS. However, a clear relationship between these high ozone days and either VOC levels or NO and CO levels was not observed. This may reflect the fact that ozone level is controlled by both advection and local photochemistry.

The observations for $\mathrm{XK}$ are displayed as a time series in Fig. 6. The NO levels were significantly lower at XK than at GZ. The XK CO levels, on average, also were lower. In addition, the correlations between NO and CO enhancements at XK were much weaker than those for GZ. Large VOC enhancement episodes, with levels more than a factor of two greater than the typical values, occurred seven times between 7 October and 18 October. Total VOC level peaked at over $277 \mathrm{ppbv}$ at XK on the morning of 12 October, but few corresponding changes occurred in $\mathrm{NO}$ and $\mathrm{CO}$ (Fig. 6a). The $\mathrm{O}_{3}$ 


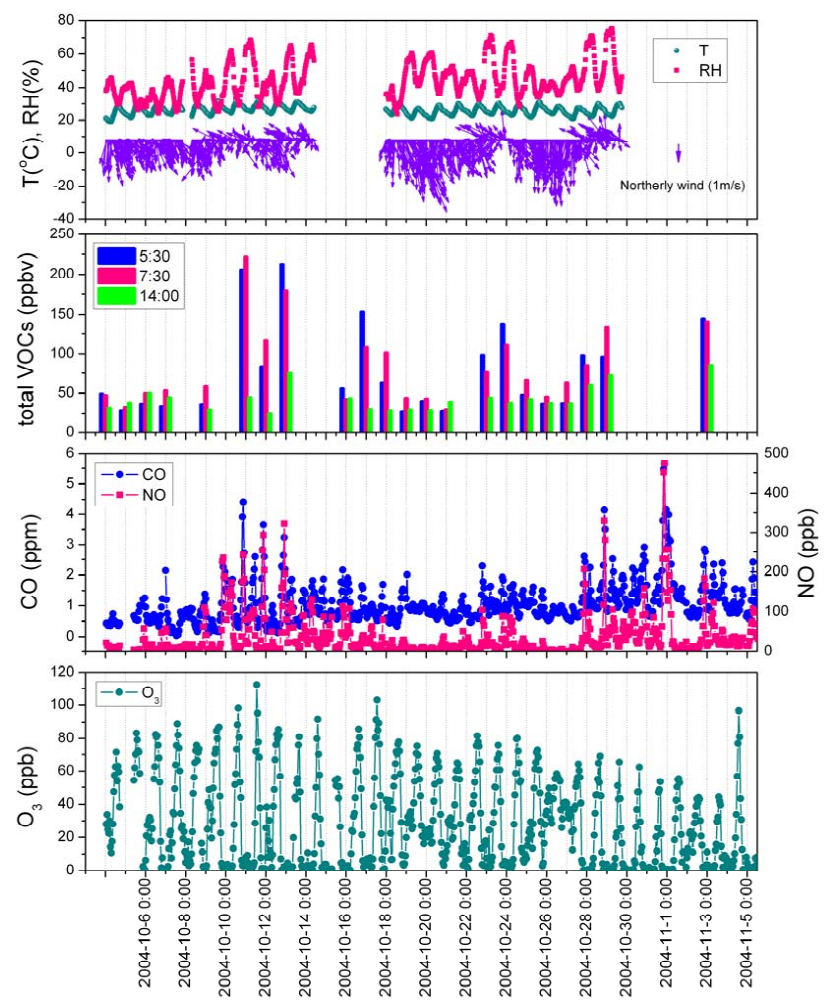

Fig. 5. Time series of measured $\mathrm{O}_{3}, \mathrm{CO}, \mathrm{NO}$, total VOCs, temperature, relative humidity, wind direction, and speed at Guangzhou during the campaign.

levels observed in XK exceeded 80 ppbv on 23 days within the study period, and were generally higher than those seen at GZ.

Figure 7 compares the episode days versus background (or normal) conditions at GZ and XK. The average of the relative contributions from alkanes, alkenes, and aromatics remained quite constant or fluctuated within a narrow range at GZ and XK (Fig. 7a). This suggests that the high VOC levels during the episode days are likely due to meteorological conditions favorable for accumulation of pollutants. Figure $7 \mathrm{~b}$ illustrates that during the pollution episodes at GZ, total VOC levels were about 2-4 times higher than those in non-episode days.

\subsection{Diurnal variation at Guangzhou and Xinken}

\subsubsection{Guangzhou}

Figure 8 illustrates the diurnal patterns of primary and secondary pollutants, using data from 21 October at the GZ site as an example. The diurnal trend of total VOCs followed a pattern similar to that of the primary pollutants, such as $\mathrm{CO}$ and $\mathrm{NO}$, but it differed from that of $\mathrm{O}_{3}$. The $\mathrm{NO}$ levels were generally over $50 \%$ of the $\mathrm{NO}_{\mathrm{y}}$ concentrations, implying that the air masses were influenced by fresh emissions. Further-

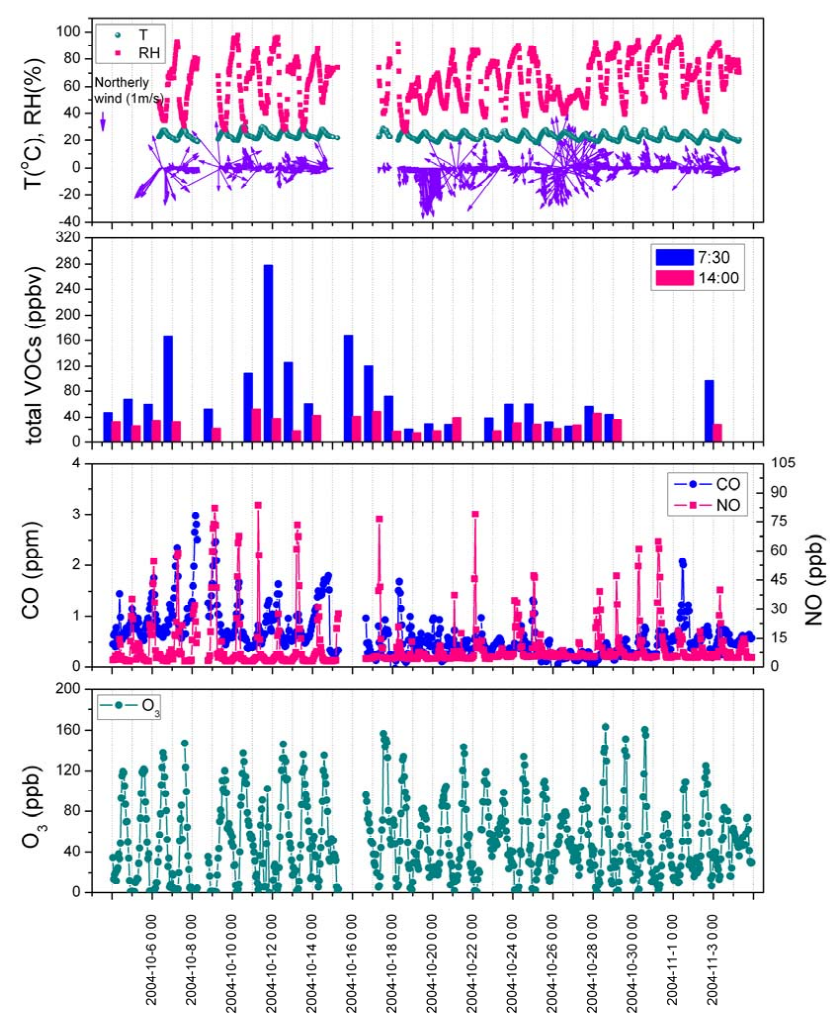

Fig. 6. Time series of measured $\mathrm{O}_{3}, \mathrm{CO}, \mathrm{NO}$, total VOCs, temperature, relative humidity, wind direction, and speed at Xinken during the campaign.

more, the diurnal variation of the $\mathrm{NO}, \mathrm{NO}_{\mathrm{y}}, \mathrm{CO}$ and total VOCs generally followed the traffic pattern of Guangzhou City. The morning and late afternoon peaks were coincided with traffic rush hours. The highest levels of VOCs, CO and NO at 20:00 21:00 were probably attributed to the heavy traffic for traditional nighttime activities in the city and the descent of boundary layer height at night. The evening peak of $\mathrm{SO}_{2}$, indicating coal burning emissions from industrial boilers, also reflected the influence of lower nocturnal boundary layer.

\subsubsection{Xinken}

The diurnal patterns of VOC gases measured at XK were quite different from those at GZ (Fig. 9). CO and VOC tracked each other on 9 October, whereas no consistent diurnal variation for either $\mathrm{CO}$ or VOCs occurred on 21 October. Unlike at GZ, ambient NO remained at much lower levels and constituted only a small fraction of $\mathrm{NO}_{\mathrm{y}}$, suggesting that the air masses were more chemically aged at XK. The ambient $\mathrm{NO}$ and $\mathrm{NO}_{\mathrm{y}}$ spikes occurred around 10:00-11:00 a.m. on both 9 October and 21 October, causing distinct decreases in $\mathrm{O}_{3}$ due to titration. As no corresponding enhancement in $\mathrm{CO}$ and VOCs occurred and $\mathrm{SO}_{2}$ displayed a similar trend as $\mathrm{NO}_{\mathrm{y}}$, these plumes probably originated from power plant 

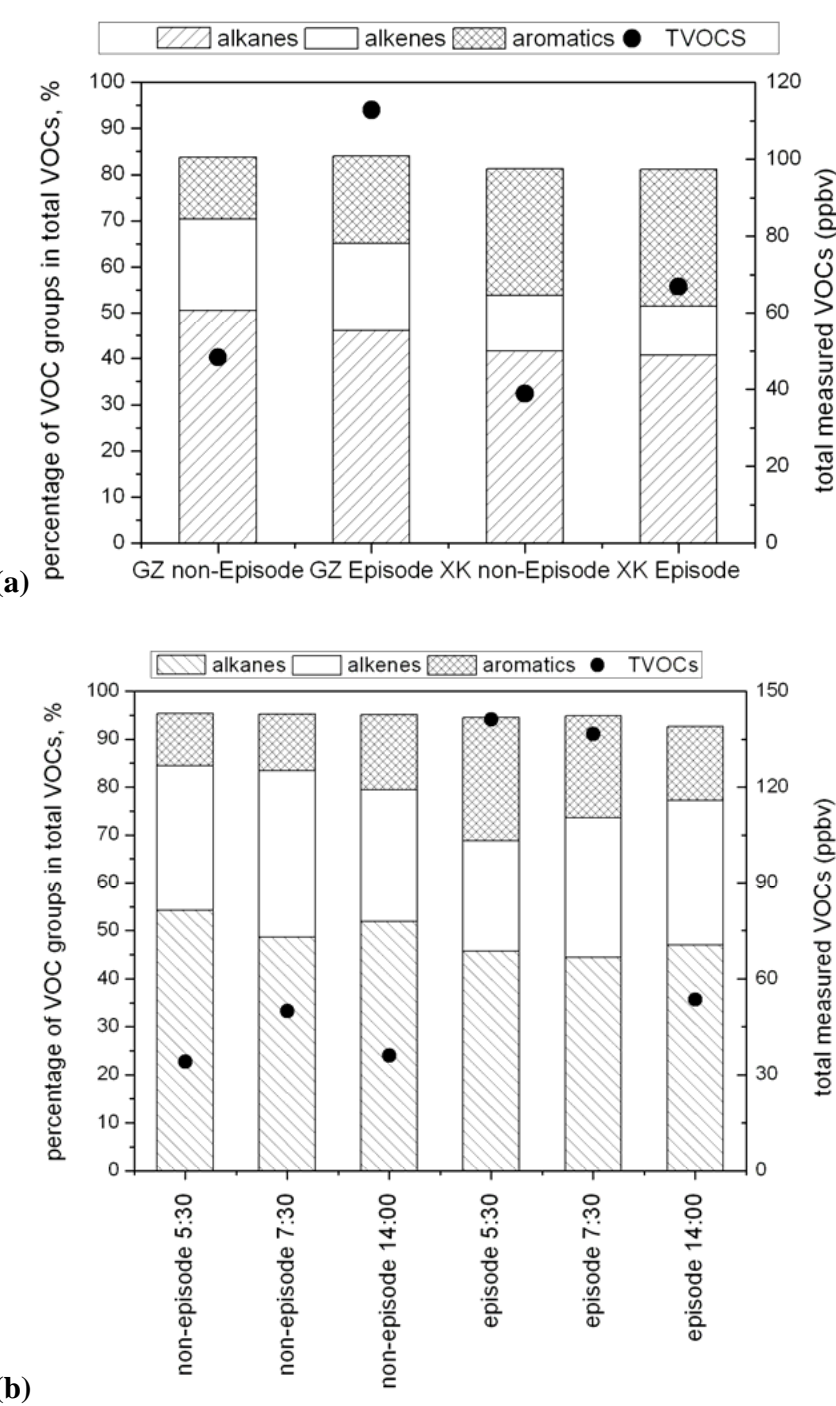

(b)

Fig. 7. (a) The average compositions and total concentration of VOCs at Guangzhou and Xinken during the first polluted episode and during non-episode days, and (b) the average composition and total concentration of VOCs at 05:30 and 07:30 at Guangzhou during the first polluted episode and during non-episode days.

emissions from upwind areas. The observations at XK suggest that advection transport likely has a larger impact on local air quality than do the local traffic sources.

Ozone had higher peak concentrations and much rapid variations at XK than those recorded in GZ. The higher ozone levels at XK were accompanied by lower levels of VOCs and $\mathrm{NO}$, indicating that the ozone did not result solely from local photochemistry. As XK lies downwind of an urban region, the mixing ratios of VOCs in the early morning were higher than those from the same time period at GZ because of the accumulation of VOCs at night as well as transport from upstream urban areas. This phenomenon appears to be more

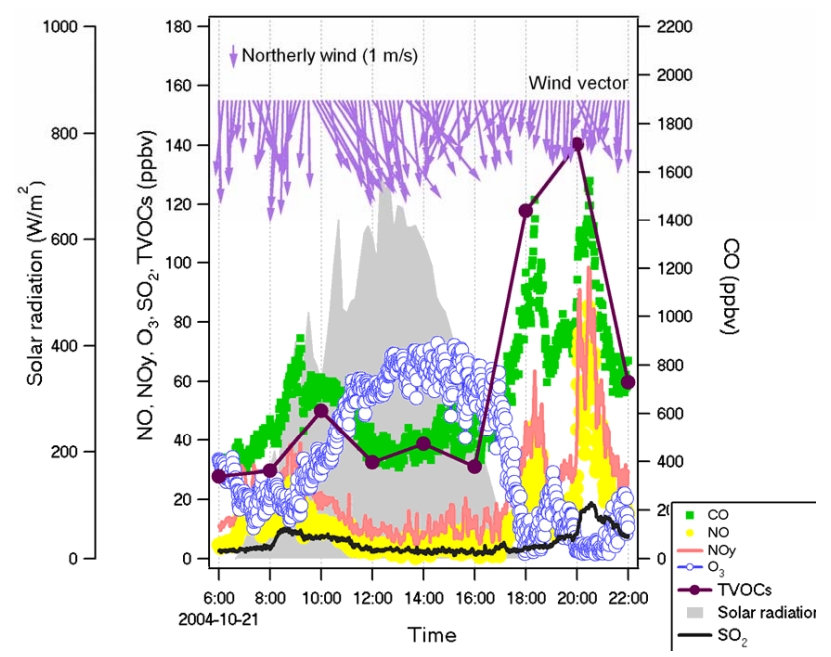

Fig. 8. Diurnal variations of TVOCs, $\mathrm{CO}, \mathrm{NO}, \mathrm{NO}_{\mathrm{y}}, \mathrm{SO}_{2}$ and $\mathrm{O}_{3}$ at Guangzhou on 21 October, 2004.

Table 4. The $\mathrm{OH}$ loss rate $\left(\mathrm{s}^{-1}\right)$ of major VOC groups at Guangzhou and Xinken during the campaign in 2004.

\begin{tabular}{lcccc}
\hline Sampling sites & Alkanes & Alkenes & Aromatics & Isoprene \\
\hline Guangzhou & $1.9 \pm 1.5$ & $8.8 \pm 6.8$ & $2.9 \pm 2.7$ & $0.5 \pm 0.4$ \\
Xinken & $1.2 \pm 1.3$ & $3.2 \pm 3.4$ & $3.2 \pm 4.5$ & $0.4 \pm 0.4$ \\
\hline
\end{tabular}

apparent during periods of northerly wind. The wind vectors at XK display a diurnal pattern; frequently, the northerly wind shifted to the south during the nighttime hours or in the early morning, and the land-sea breeze circulation had some effects on the convection and recirculation of air pollutants in the region.

\subsection{VOC reactivity at Guangzhou and Xinken}

$\mathrm{OH}$ loss rate $\left(L_{\mathrm{OH}}\right)$ is frequently used as a gauge to measure the initial peroxy radical $\left(\mathrm{RO}_{2}\right)$ formation rate, which might be the rate-limiting step in ozone formation in polluted air (Carter, 1994). While this approach does not account for the full atmospheric chemistry of the compounds considered, it does provide a simple approach to evaluate the relative contribution of individual VOCs to daytime photochemistry (Goldan et al., 2004). $L_{\mathrm{OH}}$ is calculated as the product of the $\mathrm{OH}$ reaction rate coefficient $\left(k_{i}^{\mathrm{OH}}\right)$ and the ambient mixing ratio $\left([\mathrm{VOC}]_{i}\right)$ of a given compound:

$L_{\mathrm{OH}}=[\mathrm{VOC}]_{i} \times \mathrm{k}_{i}^{\mathrm{OH}}$

We used Atkinson and Arey's (2003) published $k_{i}^{\mathrm{OH}}$ (Atkinson and Arey, 2003).

Table 4 lists the $\mathrm{OH}$ loss frequencies of the main VOC groups at GZ and XK. Of the anthropogenic VOCs, reactive 

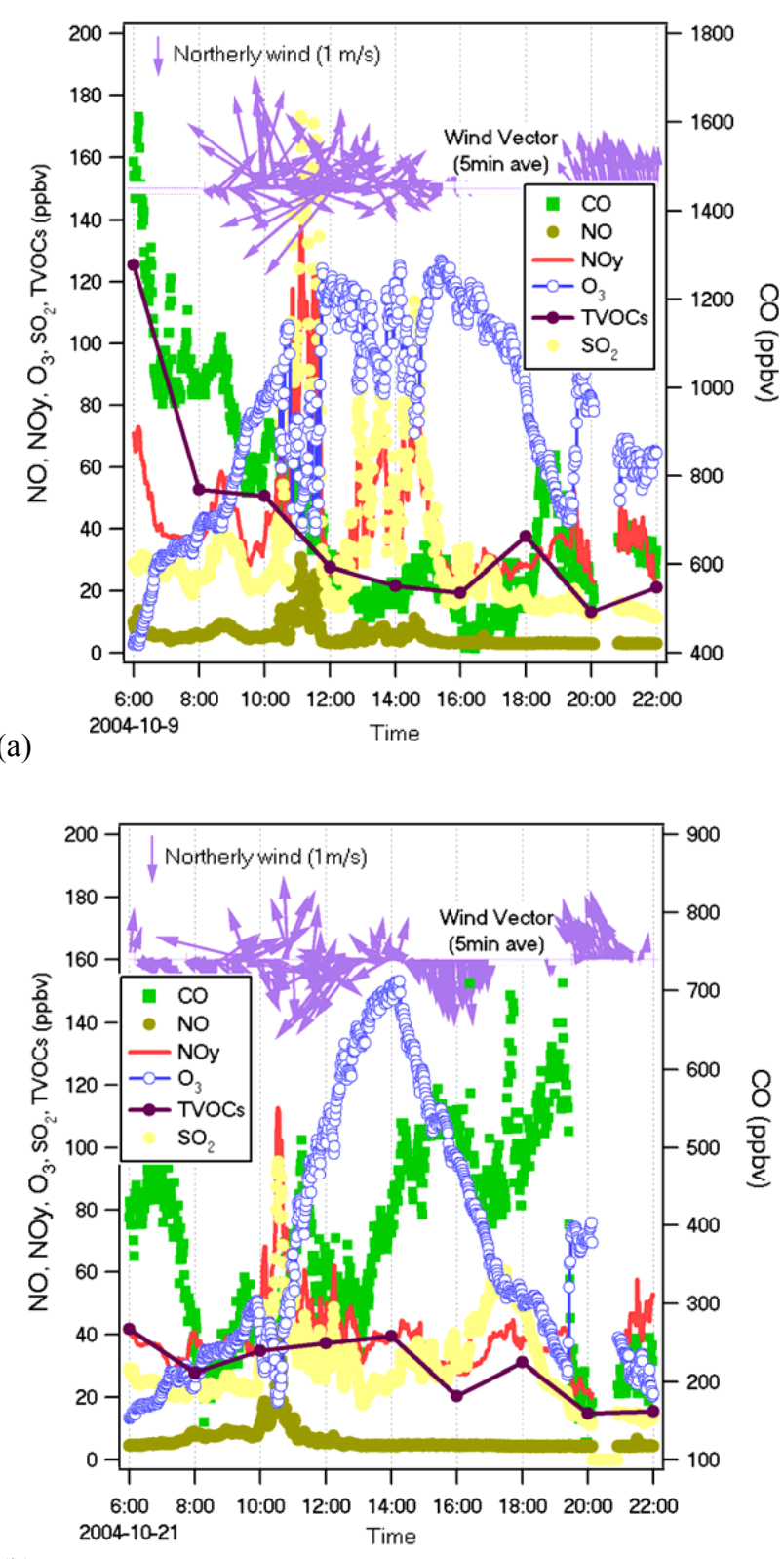

(b)

Fig. 9. Diurnal variations of TVOCs, $\mathrm{CO}, \mathrm{NO}, \mathrm{NO}_{\mathrm{y}}, \mathrm{SO}_{2}$ and $\mathrm{O}_{3}$ at XK on (a) 9 October and (b) 21 October, 2004.

olefins dominated the reactivity at GZ. The alkenes at GZ represented $28.9 \%$ of the overall mixing ratios of the measured VOCs and ranged from 24.7 to $305.5 \mathrm{ppbv}$, and they accounted for over $65 \%$ of the overall $L_{\mathrm{OH}}$ s. In contrast, the alkanes represented $47.1 \%$ of the overall mixing ratios but only a small fraction (13\%) of the overall $L_{\mathrm{OH}} \mathrm{s}$. The contribution of aromatics to VOC reactivity was $\sim 20 \%$, which was comparable with its percentage of the total mixing ratios.

At XK, the overall $L_{\mathrm{OH}} \mathrm{S}$ were lower than those at GZ, and the relative contributions from aromatics and alkenes to
VOCs reactivity were similar. At lower mixing ratios of total VOCs, the $L_{\mathrm{OH}^{\mathrm{S}}} \mathrm{s}$ of alkenes exceeded those of aromatics, and with an increase of the total mixing ratios, the contributions of aromatics were enhanced. For more polluted air, the roles of aromatics were more important in photochemical processes.

Because alkenes and aromatics played significant roles in the reactivity of VOCs at GZ and XK, in the subsequent discussion we focus on the contributions of different species of alkenes and aromatics at the two sites. At GZ, all alkenes were classified into groups by their carbon number (Fig. 10a). The most important contributors to the $L_{\mathrm{OH}^{\mathrm{S}}} \mathrm{s}$ was $\mathrm{C}_{4}$ alkenes (butenes), closely followed by propene and pentenes. Isoprene was not the dominant species as expected; this can be explained by the low emissions from plants in the urban center. In the case of clean air, the contribution of isoprene and monoterpenes was slightly increased. Hexenes and heptenes played a smaller role in $\mathrm{OH}$ loss due to their low concentrations. Figure 10b shows the percentages of aromatic groups at XK. Together with xylenes, toluene played a predominant role in the reactivity of VOCs. Although trimethyl-benzenes had larger rate coefficients, they made a minor contribution because of their low concentrations. The contribution of benzene, which was the most inert compound among the observed aromatics, decreased from the clean air to the polluted air.

\subsection{Identification of VOC sources at Guangzhou and Xinken}

Determining the PRD VOC sources was a rather complex task because it involved numerous sources in different cities. To assess the VOC sources for four major groups - alkanes, alkenes, isoprene, and aromatics - we examined correlations among the measured ambient VOC species and compared them with the known correlations from primary emission sources.

Acetylene usually is associated with sources of incomplete combustion of different fuels, such as combustion of gasoline, diesel, and LPG in vehicles, domestic use of LPG for cooking (Blake and Rowland, 1995; Goldan et al., 2000) and biomass burning (de Gouw et al., 2004). We used methyl tert-butyl ether (MTBE), a gasoline additive used to enhance its octane rating and combustion efficiency, as an indicator for mobile sources including exhaust of gasolinepowered vehicles and gasoline evaporation (Blake and Rowland, 1995; Chang et al., 2003). Figure 11 shows strong correlations of acetylene and ethylene with MTBE at GZ. Thus, it is reasonable to conclude that gasoline-powered vehicles are mostly likely the major sources of acetylene and ethylene at GZ.

The ratios of ambient concentrations of two hydrocarbons with similar reactivity remain constant at the value equal to their relative emission rates from sources (Goldan et al., 2000; Jobson et al., 2004). As mentioned above, the $\mathrm{C}_{4}$ - 


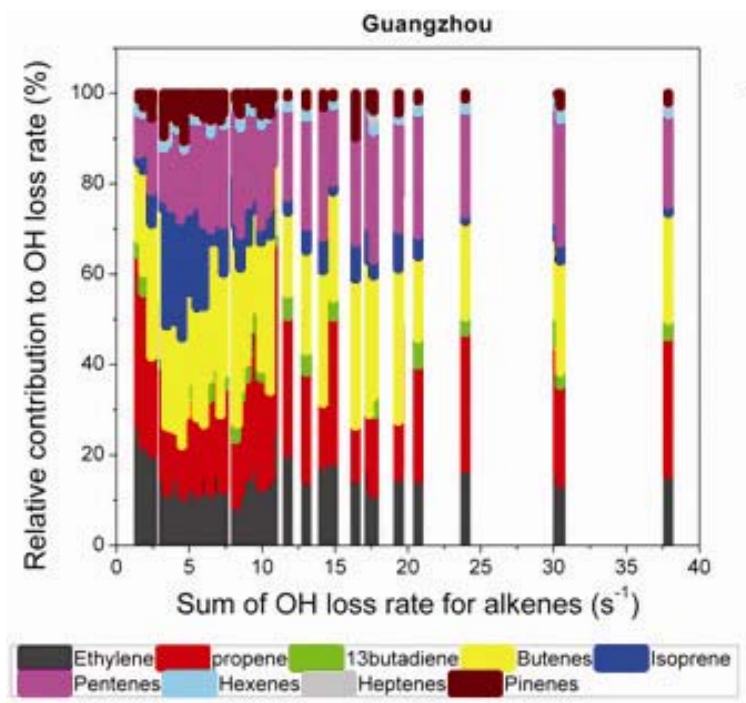

(a)

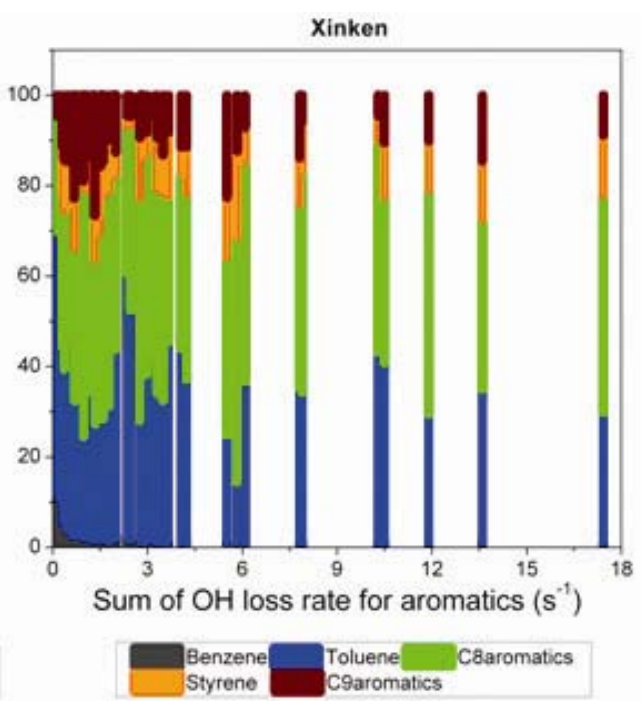

(b)

Fig. 10. Relative contribution of measured alkenes and aromatics to $\mathrm{OH}$ loss rate at Guangzhou and Xinken, respectively.

$\mathrm{C}_{5}$ alkenes were the most reactive groups at GZ. Correlations between selected butene and pentene parings with similar $k_{\mathrm{OH}}$ values are shown in Fig. 12, compared to the results obtained from the Guangzhou Pearl River Tunnel samples in September 2004 (Fu et al., 2005). The trans-2-butene and cis-2-butene in the atmosphere at GZ displayed excellent correlation with the tunnel samples; the slope of the regression line of ambient data (1.067) is very close to that of the tunnel samples (1.074). The trans/cis-2-pentenes obtained at GZ and XK correlated to each other very well, and again the regression line fit nicely with the trans/cis-2-pentenes data points measured from the tunnel experiment (Fig. 12b). The trans/cis-2-pentenes levels obtained at XK were more scattered than that from GZ site at the lower concentrations of these two species, which were likely impacted by other sources. These findings suggest that reactive 2-butenes and 2-pentenes at GZ and XK resulted primarily from vehicle exhaust emissions.

The widespread use of LPG can be another significant source of VOCs. Propane is one of the important components of LPG fuel. For LPG-powered vehicles, major emissions include light alkanes (i.e., propane, isobutene, and nbutane) as well as some alkenes (e.g., butenes). The correlations of n-butane and isobutane with propane were significant (Fig. 13) at GZ with slopes of 0.48 (correlation coefficient $r=0.97$ ) and 0.28 (correlation coefficient $r=0.97$ ), respectively. The values of these two slopes agree well with those measured in Mexico City (0.458 and 0.210), where VOCs originated mainly from LPG leakage (Blake and Rowland, 1995). These correlations suggest that gasoline-powered vehicles and LPG use are two important sources of light alkanes.

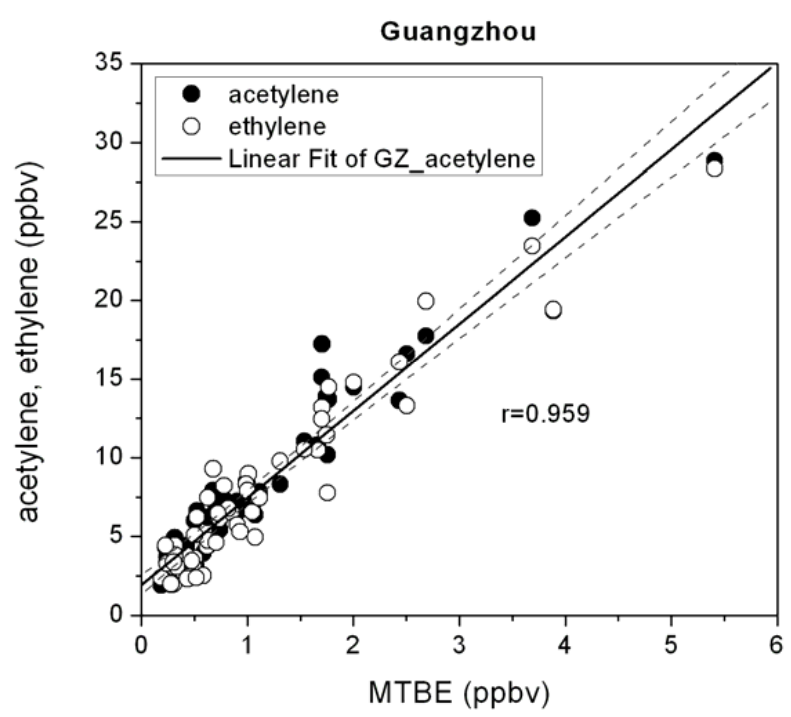

Fig. 11. Correlations of acetylene and ethylene with MTBE at Guangzhou. The solid line is the regression line of the dots, and the area within the dashed lines is the $95 \%$ confidence interval.

Acetylene and propane have similar photochemical lifetimes but come from different sources: incomplete combustion of fossil fuels or straws and LPG leakage, respectively. The ratio of these two compounds at a given site can be used to assess the relative importance of these two types of sources (Goldan et al., 2000; Zhang et al., 2004). The ratios of acetylene and propane at different sites provide an overview on a regional scale of the relative importance of these two sources to ambient alkane species levels. Figure 14a shows the plot of acetylene versus propane at six sites $(\mathrm{GZ}, \mathrm{XK}, \mathrm{CH}, \mathrm{HZ}$, 


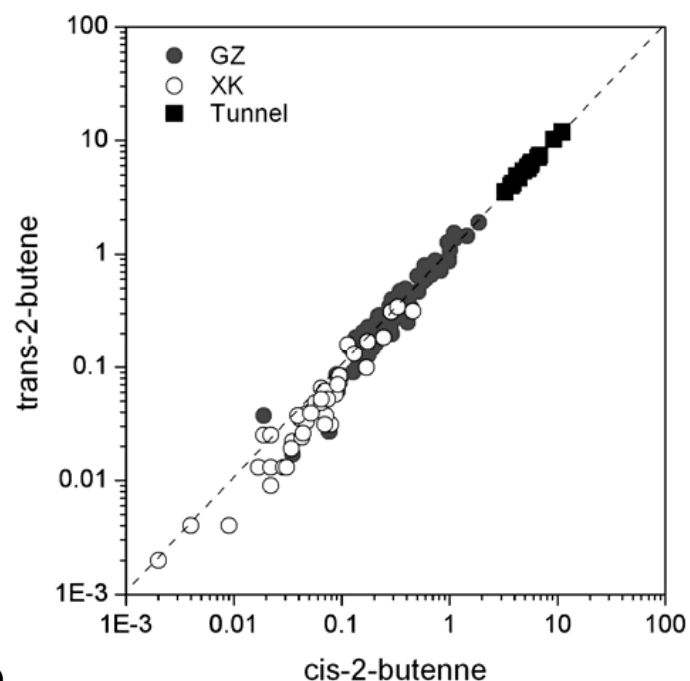

(a)

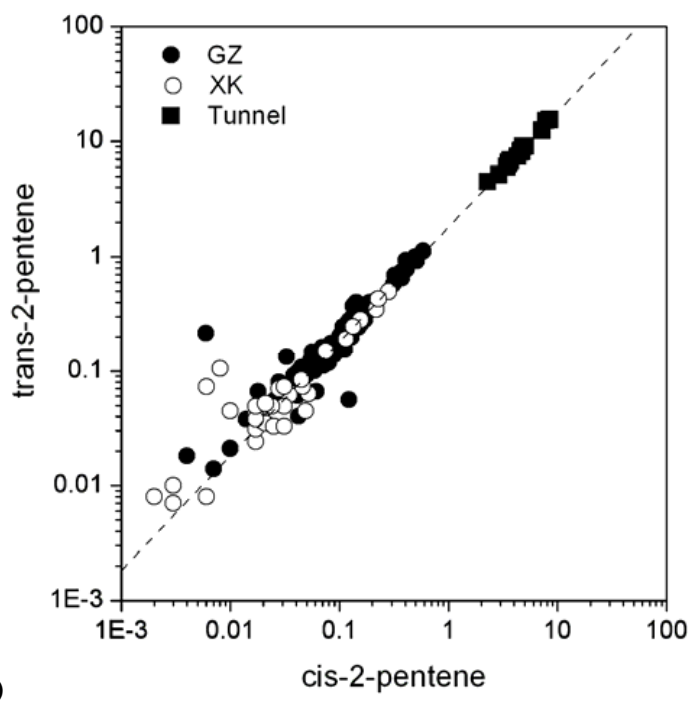

(b)

Fig. 12. Correlations between (a) trans-2-butene and cis-2-butene and (b) trans-2-pentene and cis-2-pentene at Guangzhou (solid dots) and Xinken (open circles) compared with Pearl River Tunnel samples (solid squares).

FS, and ZS). The ratios measured at XK, FS, and ZS agreed well with those reported by Seila et al. (1989) for 39 urban locations in the US (dashed line in Fig. 14). XK, FS, and ZS had a ratio of acetylene to propane that characterizes an area mostly influenced by vehicle exhaust emissions. The regression line of the GZ data diverged slightly from the dashed line, and the slope of the acetylene versus propane (0.556) regression at GZ was smaller than that measured in the samples related to mobile sources. These findings imply that LPG leakage contributed more to ambient VOCs at GZ than at the other sites, probably due to the higher percentage of LPG used for residential energy and public transportation in Guangzhou City.

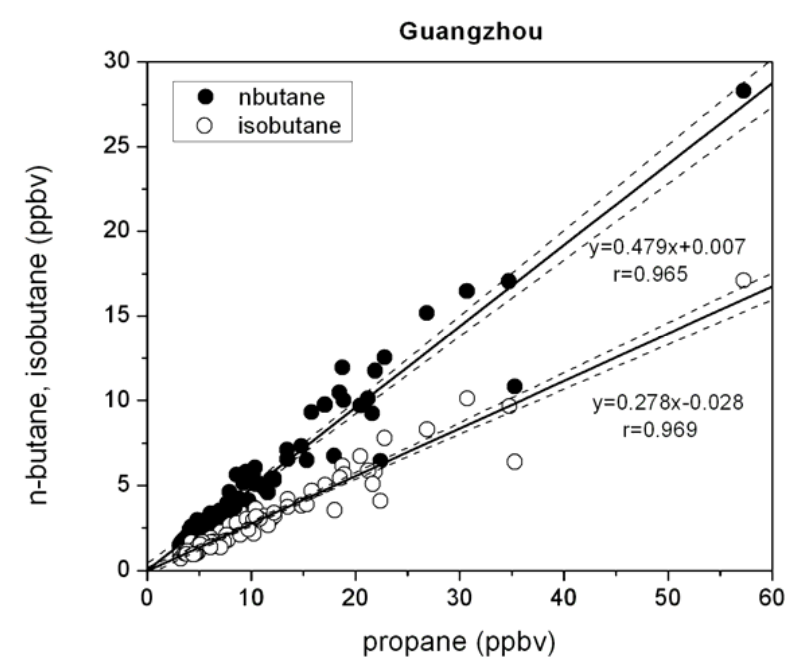

Fig. 13. Correlations between propane and n-/iso-butane at Guangzhou. The solid line is the regression line of the dots, and the area within the dashed lines is the $95 \%$ confidence interval.

The major source of benzene is vehicular emissions, whereas toluene is associated with industrial emissions, solvent and fuel storage, and vehicle exhaust (Bravo et al., 2002; Wang et al., 2002; Na et al., 2003). Toluene was the most abundant VOC species observed in industrial areas of the PRD; it is emitted directly from shoemaking, printing, leather manufacturing, furniture making, coating and chemical bonding agent production, and other chemicals plants (He et al., 2002; Chan et al., 2006). In this study we used the toluene/benzene ratio as a tool to evaluate the relative importance of vehicular and industrial emissions on a regional basis. Figure 14b shows the correlations between toluene and benzene at GZ, XK, and DG compared with those measured from tunnel samples in previous studies (Fu, 2005; Fu et al., 2005). The slopes of toluene versus benzene at XK and DG were similar; in both locales shoemaking is a major industry housed in widespread factories. The higher toluene levels at XK were impacted by the additional input of industrial emissions from DG that were advected to XK from DG. The GZ data fell between the linear regression lines of the tunnel and DG data, suggesting that ambient toluene at GZ was affected by both automotive and industrial sources.

Isoprene is one of the most reactive hydrocarbon species and is used as a tracer for biogenic emissions. Vehicular exhaust also is a source of isoprene in cities (Borbon et al., 2001). A good correlation $(r=0.91)$ was found between isoprene and 1,3-butadiene in samples collected at the Pearl River tunnel (Fig. 15). However, the mixing ratios of ambient isoprene did not correlate so well with 1,3-butadiene measurement from the GZ site $(r=0.51)$. Thus, the ambient data falling on the vicinity of the regression line from tunnel samples were probably due to vehicle exhaust, and the data points above the line with higher isoprene concentrations were likely attributed to biogenic sources. 


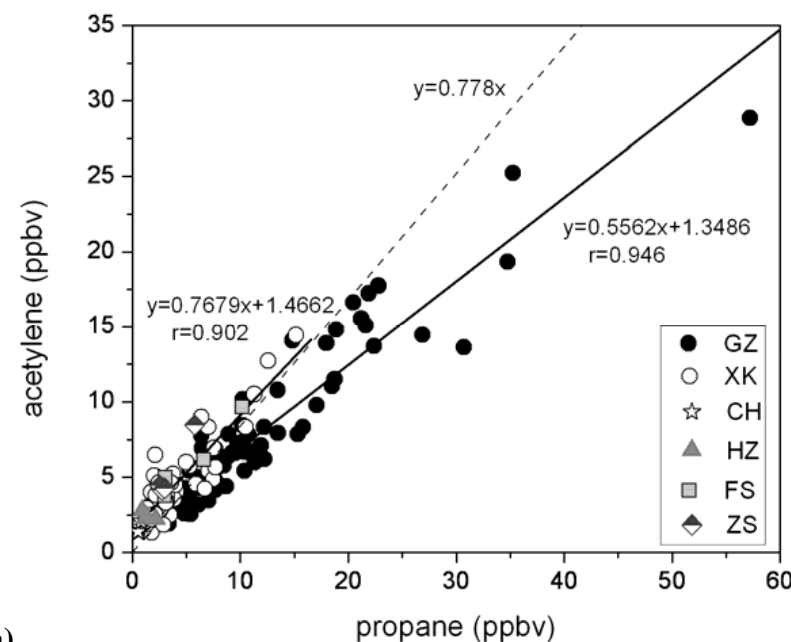

(a)

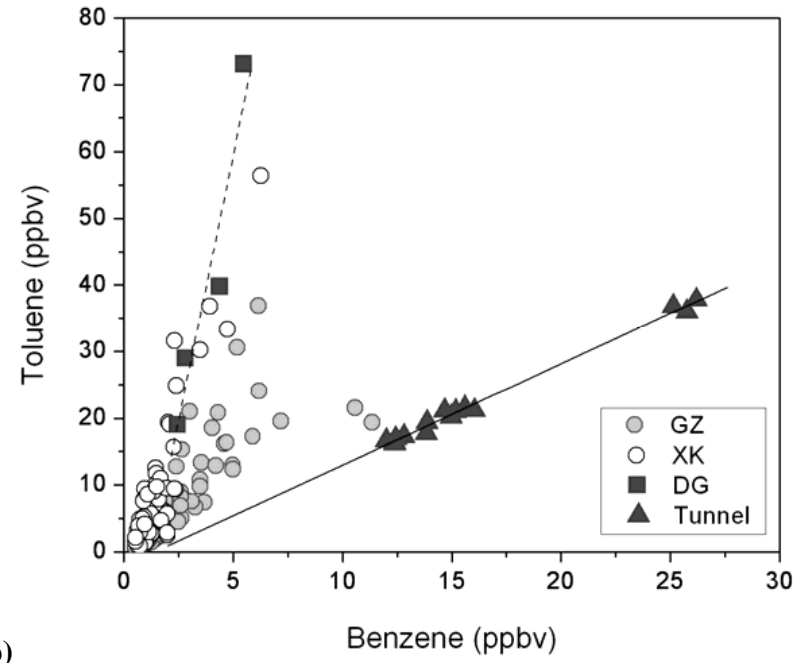

Fig. 14. (a) The correlation between acetylene and propane for six sites (Guangzhou (GZ), Xinken (XK), Conghua (CH), Huizhou (HZ), Foshen (FS), and Shongshan (ZS)), with a comparison with 39 cities studied in the US (shown as the dashed line); (b) The correlation between toluene and benzene for GZ, XK, and Dongguan (DG), comparing ambient data to the Pearl River Tunnel study (solid squares). The solid and dashed lines represent the regression lines for the results from tunnel samples and ambient data at DG, respectively.

\section{Conclusions}

Mixing ratios and chemical speciation of VOCs were measured intensively at GZ and XK as well as at five more sites in the 2004 Air Quality Monitoring Campaign in the PRD. We quantified up to 134 VOCs species, and the total VOC levels varied from 10 ppbv to over 200 ppbv. GZ had a very high level of propane, whereas Xinken, the suburban site, had high mixing ratios of aromatics. The chemical compositions differed greatly among the seven sites, reflecting the heterogeneous distribution of VOC sources in the region.

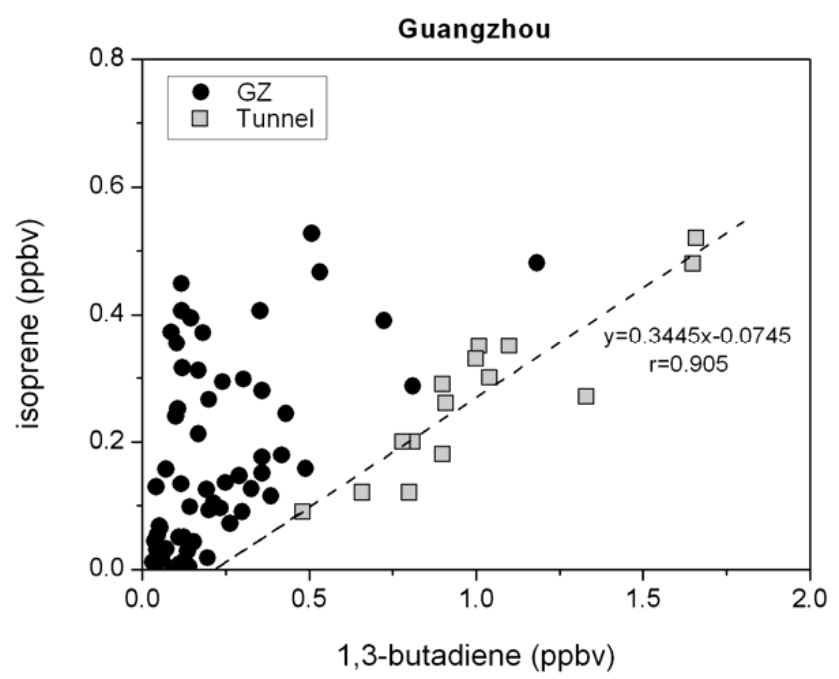

Fig. 15. The correlation between ambient isoprene and 1,3butadiene at Guangzhou, compared with the results from the Pearl River Tunnel study.

We used the $\mathrm{OH}$ loss frequency to assess the chemical reactivity of VOC species. Reactive alkenes and aromatics influenced the VOC reactivity at GZ and XK, respectively, whereas alkanes, which constituted the largest portion $(>45 \%)$ of overall VOC mixing ratios, comprised merely $<15 \%$ of the overall $\mathrm{OH}$ loss rate. At GZ, butenes showed the greatest relative contribution, closely followed by propene and pentenes; the heavier alkenes with low mixing ratios accounted for a small faction of total VOC reactivity. At $\mathrm{XK}$, toluene and $\mathrm{C}_{8}$ reactive aromatics made the largest contribution to the $\mathrm{OH}$ loss rate.

Using correlations among VOC compounds, we evaluated the relative importance of local emissions of VOCs at different sites. We attributed the ambient acetylene, ethylene, and other light alkenes at GZ to the local emissions from gasoline-powered vehicles. The high level of propane originated mostly from vehicles that consumed LPG fuel. Aromatic species at GZ were influenced by on-road vehicle emissions, industrial solvent use, and fuel evaporation. Due to the limited data about the compositions of LPG at GZ, we could not quantify the contribution of LPG exhaust and its leakage. The toluene/benzene ratio showed that VOCs were affected by emissions from solvent usage, fuel storage, and industrial emission. Before we draw a clear conclusion, however, source profiles of paint, gasoline vapor, and industrial emissions should be investigated carefully.

In comparison with the GZ site, the VOC sources that influence XK are more complex: The local emissions (from ships, biomass burning, and power plants) are coupled with transport of VOCs from cities (e.g., GuangZhou, DongGuan, and Hong Kong) depending on prevailing wind. For example, while the reactive butenes and pentenes at XK were 
primarily from local emissions, the aromatics at XK did not originate solely from local emission and likely were impacted by transport from the upwind industrial area of DG. Thus, controlling ozone levels at XK should not be confined solely to management of local emissions. Detailed investigation at the site (e.g., analysis of the VOC variation with wind direction) will be necessary for more reliable source identification of ambient VOCs.

Acknowledgements. This work was supported by the China National Natural Foundation (project number 40575059) and the National Basic Research Program of China (973) (project number 2002CB410801). G. Chen's participation in this work was supported by NASA's Tropospheric Chemistry Program. The authors would like to thank the students from RCEC, NCU, and PKU: Cheng-Hsun Lai and Chieh-Heng Wang for their continuous VOC measurements; Zhi-Ming Luo and Zhong-Ying Yu for their $\mathrm{NO}_{\mathrm{x}}, \mathrm{CO}$, and $\mathrm{O}_{3}$ measurements; and Hang $\mathrm{Su}$ for his helpful discussion of the $\mathrm{NO}_{\mathrm{x}}$ and $\mathrm{HONO}$ data.

Edited by: J. Rinne

\section{References}

Atkinson, R. and Arey, J. Atmospheric degradation of volatile organic compounds, Chem. Rev., 103(12), 4605-4638, 2003.

Barletta, B., Meinardi, S., Rowland, F. S., Chan, C. Y., Wang, X. M., Zou, S. C., Chan, L. Y., and Blake, D. R.: Volatile organic compounds in 43 Chinese cities, Atmos. Environ., 39(32), 59795990, 2005.

Batterman, S. A., Zhang, G. Z., and Baumann, M.: Analysis and stability of aldehydes and terpenes in electropolished canisters, Atmos. Environ., 32(10), 1647-1655, 1998.

Blake, D. R. and Rowland, F. S.: Urban Leakage Of Liquefied Petroleum Gas And Its Impact On Mexico-City Air-Quality, Science, 269(5226), 953-956, 1995.

Blake, D. R., Smith, T. W., Chen, T. Y., Whipple, W. J., and Rowland, F. S.: Effects of Biomass Burning on Summertime Nonmethane Hydrocarbon Concentrations in the Canadian Wetlands, J. Geophys. Res.-Atmos., 99(D1), 1699-1719, 1994.

Borbon, A., Fontaine, H., Veillerot, M., Locoge, N., Galloo, J. C., and Guillermo, R.: An investigation into the traffic-related fraction of isoprene at an urban location, Atmos. Environ., 35(22), 3749-3760, 2001.

Bravo, H., Sosa, R., Sanchez, P., Bueno, E., and Gonzalez, L.: Concentrations of benzene and toluene in the atmosphere of the Southwestern area at the Mexico City Metropolitan Zone, Atmos. Environ., 36(23), 3843-3849, 2002.

Carter, W. P. L.: Development Of Ozone Reactivity Scales For Volatile Organic-Compounds, J. Air Waste Manage., 44(7), 881899, 1994.

Chameides, W. L., Lindsay, R. W., and Richardson, J. L.: The role of biogenic hydrocarbons in urban photochemical smog: Atlanta as a case study, Science, 241, 1473-1475, 1988.

Chan, L. Y., Chu, K. W., Zou, S. C., Chan, C. Y., Wang, X. M., Barletta, B., Blake, D. R., Guo, H., and Tsai, W. Y.: Characteristics of nonmethane hydrocarbons (NMHCs) in industrial, industrialurban, and industrial-suburban atmospheres of the Pearl River
Delta (PRD) region of south China, J. Geophys. Res.-Atmos., 111(D11), D11304, doi:10.1029/2005JD006481, 2006.

Chang, C. C., Lo, S. J., Lo, J. G., and Wang, J. L.: Analysis of methyl tert-butyl ether in the atmosphere and implications as an exclusive indicator of automobile exhaust, Atmos. Environ., 37(34), 4747-4755, 2003.

Chen, T. Y., Simpson, I. J., Blake, D. R., and Rowland, F. S.: Impact of the leakage of liquefied petroleum gas (LPG) on Santiago air quality, Geophys. Res. Lett., 28(11), 2193-2196, 2001.

China Yearbook of Statistics: National Bureau of Statistics of China, 2004.

de Gouw, J. A., Cooper, O. R., Warneke, C., Hudson, P. K., Fehsenfeld, F. C., Holloway, J. S., Hubler, G., Nicks, D. K., Nowak, J. B., Parrish, D. D., Ryerson, T. B., Atlas, E. L., Donnelly, S. G., Schauffler, S. M., Stroud, V., Johnson, K., Carmichael, G. R., and Streets, D. G.: Chemical composition of air masses transported from Asia to the U.S. West Coast during ITCT 2K2: Fossil fuel combustion versus biomass-burning signatures, J. Geophys. Res.-Atmos., 109, D23S20, doi:10.1029/2003JD004202, 2004.

de Gouw, J. A., Middlebrook, A. M., Warneke, C., Goldan, P. D., Kuster, W. C., Roberts, J. M., Fehsenfeld, F. C., Worsnop, D. R., Canagaratna, M. R., Pszenny, A. A. P., Keene, W. C., Marchewka, M., Bertman, S. B., and Bates, T. S.: Budget of organic carbon in a polluted atmosphere: Results from the New England Air Quality Study in 2002, J. Geophys. Res.-Atmos., 110(D16), D16305, doi:10.1029/2004JD005623, 2005.

Fu, L. L.: The Emission Characteristics for Anthropogenic VOCs Sources in China, College of Environmental Science, Beijing, China, Peking University, Master thesis, 2005 (in Chinese).

Fu Linlin, Shao Min, Liu Yuan, Liu Ying, Lu Sihua, and Tang Dagang: Tunnel experimental study on the emission factors of volatile organic compounds (VOCs) from vehicles (in Chinese), J. Acta Scientiae Circumstantiae, 25(7), 879-885, 2005.

Goldan, P. D., Kuster, W. C., Williams, E., Murphy, P. C., Fehsenfeld, F. C., and Meagher, J.: Nonmethane hydrocarbon and oxy hydrocarbon measurements during the 2002 New England Air Quality Study, J. Geophys. Res.-Atmos., 109(D21), D21309, doi:10.1029/2003JD004455, 2004.

Goldan, P. D., Parrish, D. D., Kuster, W. C., Trainer, M., McKeen, S. A., Holloway, J., Jobson, B. T., Sueper, D. T., and Fehsenfeld, F. C.: Airborne measurements of isoprene, $\mathrm{CO}$, and anthropogenic hydrocarbons and their implications, J. Geophys. Res.-Atmos., 105(D7), 9091-9105, 2000.

Greenberg, J. P., Zimmerman, P. R., Pollock, W. F., Lueb, R. A., and Heidt, L. E.: Diurnal Variability of Atmospheric Methane, Nonmethane Hydrocarbons, and Carbon-Monoxide at Mauna-Loa, J. Geophys. Res.-Atmos., 97(D10), 10395-10 413, 1992.

Guo, H., Wang, T., Blake, D. R., Simpson, I. J., Kwok, Y. H., and Li, Y. S.: Regional and local contributions to ambient nonmethane volatile organic compounds at a polluted rural/coastal site in Pearl River Delta, China, Atmos. Environ., 40(13), 23452359, 2006.

He, J., Chen, H. X., Liu, X. X., Hu, J. H., Li, Q. L., and He, F. Q.: The analysis of various volatile solvents used in different industries in Zhongshan, South China Journal of Preventive Medicine, 28(6), 26-27, 2002 (in Chinese).

Jobson, B. T., Berkowitz, C. M., Kuster, W. C., Goldan, P. D., Williams, E. J., Fesenfeld, F. C., Apel, E. C., Karl, T., Lonneman, W. A., and Riemer, D.: Hydrocarbon source signatures in Hous- 
ton, Texas: Influence of the petrochemical industry, J. Geophys. Res.-Atmos., 109(D24), D24305, doi:10.1029/2004JD004887, 2004.

Li, G. Y., Tang, X. L., Bi, X. H., Yi, F., Sheng, G. Y., and Fu, J. M.: Composition and mutagenicity of particle sized fraction from urban particulate matter in Guangzhou City, J. Acta Scientiae Circumstantiae, 25(3), 319-323, 2005.

Liu, Y., Shao, M., Zhang, J., Fu, L. L., and Lu, S. H.: Distributions and source apportionment of ambient volatile organic compounds in Beijing city, China, J. Environ. Sci. Heal. A, 40(10), 1843-1860, 2005.

Na, K., Kim, Y. P., and Moon, K. C.: Diurnal characteristics of volatile organic compounds in the Seoul atmosphere, Atmos. Environ., 37(6), 733-742, 2003.

Ochiai, N., Tsuji, A., Nakamura, N., Daishima, S., and Cardin, D. B.: Stabilities of 58 volatile organic compounds in fused-silicalined and SUMMA polished canisters under various humidified conditions, J. Environ. Monitor., 4(6), 879-889, 2002.

Ryerson, T. B., Trainer, M., Angevine, W. M., Brock, C. A., Dissly, R. W., Fehsenfeld, F. C., Frost, G. J., Goldan, P. D., Holloway, J. S., Hubler, G., Jakoubek, R. O., Kuster, W. C., Neuman, J. A., Nicks, D. K., Parrish, D. D., Roberts, J. M., and Sueper, D. T.: Effect of petrochemical industrial emissions of reactive alkenes and NOx on tropospheric ozone formation in Houston, Texas, J. Geophys. Res.-Atmos., 108(D8), 4249, doi:10.1029/2002JD003070, 2003.

Seila, R. L., Lonneman, W. A., and Meeks, S. A.: Determination of $\mathrm{C} 2$ to $\mathrm{C} 12$ ambient air hydrocarbons in 39 U.S. cities, from 1984 through 1986, Washington, D.C., US Environ. Prot. Agency, Rep. EPA/600/S3-89/059, 1989.

Shao, M., Zhao, M. P., Zhang, Y. H., Peng, L. X., and Li, J. L.: Biogenic VOCs emissions and its impact on ozone formation in major cities of China, J. Environ. Sci. Heal. A, 35(10), 19411950, 2000.
Wang, T., Guo, H., Blake, D. R., Kwok, Y. H., Simpson, I. J., and Li, Y. S.: Measurements of trace gases in the inflow of South China Sea background air and outflow of regional pollution at Tai O, Southern China, J. Atmos. Chem., 52(3), 295-317, 2005.

Wang, T., Poon, C. N., Kwok, Y. H., and Li, Y. S.: Characterizing the temporal variability and emission patterns of pollution plumes in the Pearl River Delta of China, Atmos. Environ., 37(25), 3539-3550, 2003.

Wang, X. M., Sheng, G. Y., Fu, J. M., Chan, C. Y., Lee, S. G., Chan, L. Y., and Wang, Z. S.: Urban roadside aromatic hydrocarbons in three cities of the Pearl River Delta, People's Republic of China, Atmos. Environ., 36(33), 5141-5148, 2002.

Warneke, C., de Gouw, J. A., Goldan, P. D., Kuster, W. C., Williams, E. J., Lerner, B. M., Jakoubek, R., Brown, S. S., Stark, H., Aldener, M., Ravishankara, A. R., Roberts, J. M., Marchewka, M., Bertman, S., Sueper, D. T., McKeen, S. A., Meagher, J. F., and Fehsenfeld, F. C.: Comparison of daytime and nighttime oxidation of biogenic and anthropogenic VOCs along the New England coast in summer during New England Air Quality Study 2002, J. Geophy. Res.-Atmos., 109(D10), D10309, doi:10.1029/2003JD004424, 2004.

Zhang, J., Chameides, W. L., Wang, T., and Kiang, C. S.: Final Report: HongKong and the Pearl River Delta Pilot Air Monitoring Project: Pilot study on the use of atomospheric measurements to manage air quality in Hong Kong and the Pearl River Delta Project 1: Ground-level Ozone Pollution in Hong Kong, Civic Exchange, Hong Kong, 2004.

Zhang, Y. H., Shao, K. S., and Tang, X. Y.: The Study of Urban Photochemical Smog Pollution in China, Acta Scientiarum Natrualium, Universitatis Pekinenesis, 24(2-3), 392-400, 1998 (in Chinese). 